\title{
Examining the Existence of a Modified Environmental Kuznets Curve for the Middle East and North Africa Economies
}

\author{
By Hanan Hamed M. Sileem ${ }^{1}$
}

\begin{abstract}
Most of the environment-income relationship literature uses the Environmental Kuznets Curve (EKC) approach to study the impact of income growth on environment degradation. However, a more realistic approach should discuss the relationship in terms of development rather than merely income growth. To reflect the development dimension, this research examines the existence of the EKC relationship between CO2 emissions per capita and Human Development Index in the MENA economies for the period 2004-2013; in what is officially known by the name of Modified EKC (MEKC). Using Least Square Fixed Effects specification, the empirical results indicate the existence of MEKC for the MENA region economies. In addition, empirical results support the significance of controlling corruption on decreasing CO2 emissions. A Granger causality test on the direction of the relationship between corruption and $\mathrm{CO} 2$ emissions per capita is examined. The results of the Granger causality test confirm the presence of a unidirectional relationship between CO2 emissions per capita and corruption. Arguing on the basis of MKEC, the empirical results show that reducing corruption can be an important factor in improving the environmental quality as well as effectively mitigate climate change in the MENA region.
\end{abstract}

Keywords: Granger causality test, corruption, climate change, MEKC, mitigation.

\section{Introduction}

Environmental degradation is a permanent concern in the MENA region, the region is dominated by the Sahara and Arabian deserts, two of the world's driest zones. Over the centuries, the unique environmental stresses of water scarcity and severely limited irrigation land have halted local societies' development in the region. However, recent decades have witnessed new developments that are consuming the region's environmental stock. Economic growth, sustained by consuming rich deposits of oil, gas, and other natural resources, has triggered population growth. This in turn has fueled urbanization, industrial development, and unsustainable agricultural practices, which accumulated more negative impacts on the environment. In fact, MENA countries produce around $7 \%$ of worldwide greenhouse gases (GHGs) while accounting for around $6 \%$ of the world's population. More importantly, in the last two decades, MENA's emissions grew by $88 \%$. This rapid increase in GHG emissions costs MENA region an environmental damage estimated at US\$ 9 billion per year (EFR, 2010). This in turn can further delay the MENA economies and imposes significant harm to livelihoods, public finances, and the economic competitiveness of the region.

Recognizing this, over the past two decades important efforts have been made, at both national and regional levels, to enhance environmental management and protection in the region. The global cost of combating and adapting to climate change is estimated at $\$ 46$ trillion up to 2050, or $\$ 1$ trillion a year (International Transparency, 2011). In particular, the MENA economies received, for instance,

${ }^{1}$ Lecturer at Economics Department, Sadat Academy for Management Sciences, 108 EL Mahata St, Giza, Egypt 
US $\$ 278.5$ million in the form of Global Environment Facility (GEF) grants to help them in building capacity, reporting emissions and tackling the climate issue. However, the misuse of these funds or the bribery in awarding contracts or grants can undermine good climate governance. To this end, the paper focuses on defining the impact of controlling corruption on mitigating the climate change. In addition, this paper focuses on addressing the relationship between $\mathrm{CO}_{2}$ emissions and development in a MEKC context rather than the usual EKC context which examines the only the income dimension The empirical findings of the current research contribute to the environment-development literature by highlighting the impact of controlling corruption on reducing the $\mathrm{CO}_{2}$ emissions as well as identifying the causality relationship between both variables using Granger casualty test for the MENA economies from 2004-2013. In section one, the paper discusses the link between environmental degradation, corruption and sustainable development. Section Two provides the empirical framework and results of testing MEKC assumption in the MENA economies. Section Three introduces granger casualty test for corruption and $\mathrm{CO}_{2}$ emissions; finally Section Four presents recommendations to reduce corruption of climate mitigation policies.

\section{The Link between Environmental Degradation, Corruption and Sustainable Development}

The accumulation of GHG emissions, i.e. the continuous rise in the global temperature due to human activities, triggered the environmental degradation. Its adverse impact on sustaining life includes lowering water resources per capita, shrinking arable land, deteriorating vulnerable coastal zones and damaging marine life, rising energy use, and mounting waste in urban areas (Dow \& Downing, 2006). More than $75 \%$ of the MENA area's population is mainly dependent on rain-fed agriculture. As most African areas, this area does not have many sustainable water infrastructures, with few exceptions, e.g. the Nile delta and Nile valley. However, there are expectations that the Nile Delta flows will decrease by $40 \%$ in 2025, because of global warming (Downie, Kate \& Vaughan, 2009). By 2050, water scarcity will be a major issue because of the expected reduction in Delta flows following the expected increase in population growth rate. Thus, water problems combined with higher levels of temperature will decrease agricultural productivity and trigger several other economical, financial and social consequences in the region. In particular, crops such as maize, which is the main source of food in the MENA region, will decrease by $15-25 \%$ with the continuous rise in temperature; in addition, around 300-1600 persons are expected to die each year because of higher temperature (Stern, 2006).

Currently, it may seem that the environmental institutions in MENA economies have witness a great shift in tackling environmental problems. However, Arab governments "bave failed to adopt clear and effective policies to limit the growing cost of environmental problems, to which the governments allocate less than 1\% of their Gross Domestic Product (GDP)". Air pollution from transportation is costing Arab economies 5 billion in damages. Environmental degradation costs Egypt $4.8 \%$ of its GDP which equals around 4.280 billion US\$. Both Morocco and Algeria are next with a loss equals 3.7\% and $3.6 \%$ of GDP because of environmental degradation. Followed by Syria (3.5\%), Lebanon (3.4\%) and Jordan $(3.1 \%$ of GDP), and finally Tunisia loses around $2.1 \%$ of its GDP due to environmental degradation (ERF, 2010).

Several climate-mitigation policies and grants have directed the MENA region toward the global environment and sustainable development by supporting innovation and the adoption of new, diversified approaches. In some cases, this has helped financing friendly-environment techniques and setting the stage for future generation projects across a variety of economic sectors, including agriculture, water, and energy, urban development, biodiversity conservation, and social development (International Transparency, 2011). At the same time, in seeking to diversify their 
growth sectors, the MENA economies have embraced a long run development based on using only natural resources.

However, the existence of effective democratic institutions that promote good accountability and transparency is crucial for sustaining effective climate change mitigation. Otherwise all the mitigation efforts will be insufficient to create large-scale, meaningful change. Effective institutions are fundamental for reducing environmental degradation. Users of environmental resources will be compelled to take in their account social costs of their actions (ERF, 2010). In addition, effective institutions can neutralize the impacts of corruption. According to the findings of the Transparency International study (2014), more than a quarter of people worldwide have given a bribe in the last twelve months when interacting with public institutions and services. The development challenge that corruption poses to climate finance has pervasive and complex factors. It includes hindering economic growth, undermining social welfare and impeding public trust and good public governance. At the national level, the risk of having public sector corruption includes officials taking bribes, or entire ministries captured by special interests, these risks could endanger achieving the targets of climate finance. In particular, corruption is responsible for underrating the effect of the transfer of around $20 \%-40 \%$ of official development assistance (UNEP, 2013). The costs of corruption are often intangible, more importantly; they impact first the poor and vulnerable groups (Gnocato, Harford, Jordan \& Shelley, 2014).

At the global level, corruption imposes an estimated cost higher than $5 \%$ of global GDP (OECD, 2014). This is due to the complexity of the development and environment systems, triggered by the existence of multiple information asymmetries, and the large amount of public and civil funds involved in both fields. On the one hand, the Global Corruption Report estimates the efforts to respond to climate change would include huge amounts of money flow through new and untested financial markets and mechanisms. There is always a risk of corruption when total climate change investments in mitigation efforts alone estimated at almost US $\$ 700$ billion by 2020 . In addition, pressure of fast-track resolutions, can further increase the risk of corruption (International Transparency, 2014).

On the other hand, corruption reduces the overall reliability and effectiveness of GHG markets. The implementation of cap-and-trade systems in both developed and developing economies is delayed because of fraud and bribery, abuses of power, the manipulation of GHG market prices and other traditional forms of corruption. Corruption risks extend to new areas because of the level of complexity, uncertainty and novelty that surrounds many climate issues, e.g. identifying essential environmental concepts e.g. forest, or measuring the environmental integrity of carbon offsets. There are also many regulatory grey zones and loopholes that are at risk of being exploited by corrupt interests. In 2012, United Nations Conference on Sustainable Development explicitly recognized that corruption is an impediment to an effective environmental policy (UNEP, 2013).

The total cost of corruption becomes more complicated when considering the socio-economic and cultural norms that directly impact sustainable development. Sustainable development is "meeting the needs of the present generations without compromising the ability of future generations to meet their own needs" (WCED, 1987). To this end, Pearce \& Atkinson (1993) introduced a basic assumption that an equal transfer of capital stock is a crucial condition for sustainable development. Future generations have given entrusted power to current generations to rationally manage the planet. Lack of control for corruption will limit future generations' access to resources and ignore their rights to receive equal transfer of capital stock. Corruption must be addressed for the successful allocation and effectiveness of international climate assistance and finance. 


\section{Econometric Framework}

\subsection{Theoretical Literature Review}

The original writings of Simon Kuznets (1954) about economic inequality suggested that inequality increases overtime while a country is developing, and then after a certain income is attained, inequality begins to decrease in a way that reflects an inverted $U$ shaped relationship (Yandle, Bhattarai \& Vijayaraghavan, 2002). Later, economists found this hypothesis similar to the income-pollution relationship and popularized the EKC phrase. The EKC hypothesis suggests that pollution initially increases as an economy develops its industry because of consuming more natural resources, and using technology that releases more emissions; with no regard for environmental quality. However, after reaching a certain level of economic progress or attaining higher per capita income, more attention is paid to environmental quality. This means a more cleaner and friendly-environment techniques are implemented to lower the damage to natural resources at this stage.

Following this hypothesis, as suggested by Grossman \& Krueger (1995), the relationship between environment degradation and economic development can be estimated using a reduced-form function of income per capita and income per capita square. Most EKC empirical literature uses one of two general approaches: cross section analysis, or panel data. In both cases, the model implicitly assumes that the slope of the corresponding relationship is the same for every country in the sample, while the constant may be different. Since the EKC is a quadratic relationship, this constant coefficient assumption implies that every economy follows the same EKC shape. Thus, the ability of the cross-section estimation to reflect the variation in the nature of pollution indictors in relation with the income level across economies is limited. The assumption of a common structure within a country over time is probably more reasonable than that of a common structure across countries, given environmental, physical and social features of each economy (Costantini \& Martini, 2006; He, 2003). In fact, using panel data estimation allows additional advantages. For example, it combines inter-individual differences and intra-individual dynamics, allowing for more accurate inference on model parameters. In addition, it constructs and tests more complicated behavioral hypotheses; and finally, it allows a better treatment of multi-collinearity (Matyas \& Sevestre, 1995).

In 2006, Costantini and Martini (2006) paper considered a wider concept of development rather than pure economic growth, including well-being aspects and sustainability of the development process, in what they called a Modified EKC. They used a panel analysis for examining developed and developing countries using alternative pollutants. Using Human Development Index (HDI), the findings of the research identified correlation between human development and sustainable development, following the classic inverted $U$-shaped curve of the EKC. The level of development for the EKC corresponds to an income per capita level confirming the results showing that an increase in human well-being is necessary to provide a sustainability path. Thus, the current paper tests the validity of two hypotheses:

- There exists a Modified EKC for MENA economies.

- There exists a Granger Causality relationship between $\mathrm{CO}_{2}$ emissions and corruption.

\subsection{The Choice of Variables}

Empirical studies have made estimations using different environmental degradation indicators (i.e. pollutants). The early EKC literature focused mainly on local air pollution emissions. This was later extended to include global emissions, accumulation of wastes and natural resources extraction (Kallbekken, 2000). The dependent variable in MEKC is representing environment degradation indicator to account for the accumulation in GHG emissions causing climate change. The sulfur dioxide $\left(\mathrm{SO}_{2}\right)$ pollutant is generally believed to be the most likely 
indicator that would follow the inverted-U hypothesis (He, 2003; Olsen, 2007). Some studies indicate that the EKC shape is the strongest for particulate matter, sulfur oxides, nitrogen oxide (NOX), and carbon monoxide (Bouvier, 2004).

Nevertheless, several scholars argue that $\mathrm{CO}_{2}$ emissions can have an inverse U Shape when tested with economic development (Olsen, 2007). Furthermore, $\mathrm{CO}_{2}$ is the primary GHG triggering global warming; using $\mathrm{CO}_{2}$ as a more valid and reliable proxy for air pollution is well supported for many reasons. First, $\mathrm{CO}_{2}$ concentrations remain in the atmosphere over than 100 years unlike other air pollutants. Second, $\mathrm{CO}_{2}$ emissions constitute around 77 percent of the global warming (Banuri \& Opschoor, 2007). Moreover, $\mathrm{CO}_{2}$ is highly correlated with other pollutants; the correlation coefficient of $\mathrm{CO}_{2}$ with $\mathrm{NOX}$ and $\mathrm{SO}_{2}$ in 111 countries was estimated in 1990 to be 0.9529 and 0.9536 respectively (Hoffmann, Lee, Ramasamy, \& Yeung, 2005). Finally, there are more reliable data on $\mathrm{CO}_{2}$ emissions for several years compared to other pollutants.

The EKC literature using $\mathrm{CO}_{2}$ and $\mathrm{SO}_{2}$ emissions per capita as the dependent variable involves the use of several forms for income and emissions. However, per capita measure remains to be the most popular measure in EKC empirical literature. Following the MEKC framework argument proposed by (Kallabbern, 2000; Costantini \& Martini, 2006), the use of HDI allows a better proxy for the "level of development" than using only GDP in the standard EKC. To explore if economic development has a curvilinear effect on $\mathrm{CO}_{2}$ emissions in MENA economies, it is expected that the signs of the regression coefficients remains the same, to reflect the inverted $\mathrm{U}$ shape of the standard EKC; i.e. positive for HDI and negative for the square of HDI. As a development proxy the HDI improves upon per capita income only in respect of education and longevity. Education is expected to affect environmental awareness of the population and in general their ability to exercise their democratic rights. Longevity could affect rate of making longer planning.

\subsection{Model Specification}

To empirically perform the regression, the study estimated both the Fixed effects and Random effects specification, however, a Hausman test is used to examine the inconsistency of the Random effects estimate by comparing the Fixed effects and Random effects slope parameters. A significant difference indicates that the Random effects model is estimated inconsistently, due to correlation between the explanatory variables and the error components. In this case, the Fixed effects model can be estimated consistently (Stern, 2004). The $\mathrm{CO}_{2}$ emissions per capita in economy $i$ at time $t$ is given by using both alternative forms of the reduced MEKC function: $\quad \mathrm{Co}_{2 \mathrm{it}}=\mathrm{F}\left(\mathrm{HDI}_{\mathrm{it}}, \varepsilon_{i \mathrm{t}}\right)$

After transformation, the MEKC function in subset (1) takes the following Fixed Effects specification. Only the quadratic form of the MEKC function is estimated, since many studies have indicated that the cubic form turned to be insignificant (Kallbekken, 2000):

$$
\mathrm{Co}_{2 i t}=\alpha_{i}+\beta_{1} H D I_{i t}+\beta_{2} H D I^{2}{ }_{i t}+\varepsilon_{i t}
$$

Where: $\mathrm{i}=1,2, \ldots \ldots \mathrm{N}, \mathrm{t}=1,2, \ldots . \mathrm{T}, \mathrm{Co}_{2 i t}$ is the dependent variable which measures total $\mathrm{CO}_{2}$ emissions per capita in economy $i$ at time $t$;

$\mathrm{HDI}_{\mathrm{i}, \mathrm{t}}$ is the explanatory variable stands for Human Development Index in economy $\mathrm{i}$ at time $\mathrm{t}$.

$\mathrm{HDI}^{2}{ }_{i, t}$ is the explanatory variable accounts for the square of HDI in country $i$ at time $t$.

$\alpha_{i}$ is the unobservable country specific effects, where $\alpha_{i}=z_{i}^{\prime} \alpha$, the term $Z_{i} \alpha$ allows having heterogeneity or individual effects in the estimation; ${ }{ }_{i t}$ is the error term;

In subset (2), Arguing on the basis of the MEKC hypothesis, $\mathrm{CO}_{2}$ emissions are regressed on corruption, HDI, HDI square. This inclusion of additional variable to the classical reduced model is a familiar procedure in the literature of EKC (Yongfu \& Barker, 2009). The estimated function of MEKC in subset (2) is given by the Fixed effects specification equation: 
$C O_{2 i t}=\gamma \operatorname{Corr}_{i t}+\beta_{1} H D I_{i t}+\beta_{2} H D I_{i t}^{2}+\mu_{i}+v_{i t}$

$\mathrm{i}=1$.

19 and $\mathrm{t}=1$

. .10 Where

Corr $_{i t}$ is an explanatory variable that stands for Corruption control in country $i$ at time $t$.

$\mu_{\mathrm{i}}$ is the unobservable country specific effects where $\mu_{i}=z_{i}^{\prime} \mu$; the term $z_{i} \mu$ allow having heterogeneity or individual effects in the estimation; ${ }^{v}$ it is the error term.

$\gamma$ is expected to be $<0$. This indicates a negative relation between Corruption and $\mathrm{CO}_{2}$ emissions. In line with literature at hand, the $\mathrm{CO}_{2}$ emissions assumed to follow an inverse-U Shaped with economic development reflecting the quadratic function. This indicates that the estimated coefficient of HDI is expected to have positive sign while the estimated coefficient of the squared HDI is expected to be negative, i.e. $\beta_{1}>0$ and $\beta_{2}<0$.

\subsection{Data Construction and Sources}

The data collection begins from the year 2004 to 2013. The focus of the research is to test the developing economies that exist in the MENA region. Appendix (A) lists all the economies included in the sample. The total number of observations is 190 .

Carbon Dioxide Emissions per Capita: The dependent variable defining the environmental degradation; the data on $\mathrm{CO}_{2}$ were obtained from the World Bank Open Data Base, from year 2004 to 2013. $\mathrm{CO}_{2}$ emissions are measured in ton per capita.

HDI: The Human Development Index; it includes three dimensions of human well-being, representing the basic capabilities for individuals to achieve decent standards of living. They are: (i) a long and healthy life; (ii) access to knowledge; (iii) a decent standard of living. In order to represent such dimensions, the HDI combines some basic indicators of life expectancy at birth, education (the adult literacy rate, the gross enrolment ratio (or mean years of schooling), as well as the income (GDP) per capita to one composite index. The HDI is expressed as a value between (0 and 1), where 1 is the highest development index score. The data on HDI is obtained from the World Bank Open Data base, from year 2004 to 2013.

Corruption: It reflects perceptions of the extent to which corruption is controlled. The data on Corruption ranges from the value of -2.5 to 2.5 . The value of "-2.5" is assigned to weak governance while the value "2.5" is assigned to strong governance performance in controlling corruption. Data obtained from the Worldwide Governance Indicators from year 2004-2013.

\subsection{Empirical Results of MEKC}

First, the study runs a Hausman test, to examine the consistency of estimating the Random effects model, for the $\mathrm{CO}_{2}$ equation (Subset 1), the value of chi-square statistic for testing the differences between all coefficients is equal to 70.398638 which is higher than the critical value. Its corresponding p-value of 0.000 suggests that the null hypothesis of no correlation between the explanatory variables and the random effects should be rejected. This means estimation of Random effects specification is inconsistent. Alternatively, Fixed effects estimation is consistent as recommended by the literature (Stern, 2004). Thus, the study employs onward Fixed effects coefficients. The fixed coefficient model was estimated with and without correcting for panel-level heteroskedasticity, and then compared. Evidence was found for the existence of panel-level heteroskedasticity. The estimated results in Table (1) are reported after correcting for heteroskedasticity using the white cross section weights. 
Table 1: Empirical Results For Mena Economies After Correcting For Heteroskedasticity

\begin{tabular}{|c|c|c|}
\hline Variables & $\begin{array}{c}\text { Fixed Panel Specification } \\
\text { Subset (1) }\end{array}$ & $\begin{array}{c}\text { Fixed Panel Specification } \\
\text { Subset (2) }\end{array}$ \\
\hline \multirow[t]{2}{*}{ Constant } & $-30.77856^{\mathrm{a}}$ & $-38.98823^{\mathrm{b}}$ \\
\hline & $(-2.779400)$ & $(-2.102541)$ \\
\hline \multirow[t]{2}{*}{ CORR } & & $-4.489829 a$ \\
\hline & & $(-3.922859)$ \\
\hline \multirow[t]{2}{*}{ HDI } & $80.58358^{\mathrm{a}}$ & $103.7416^{\mathrm{b}}$ \\
\hline & $(4.014827)$ & $(2.477092)$ \\
\hline \multirow[t]{2}{*}{ SHDI } & $-30.20783^{c}$ & $-48.68435^{c}$ \\
\hline & $(-1.665115)$ & $(-1.704976)$ \\
\hline No of observations & 190 & 190 \\
\hline
\end{tabular}

The results in Table (1) dispatch an inverted $U$ shape as expected in both subsets. This is evidenced by having the expected signs of the coefficients of HDI and HDI square; where $\beta_{1}>0$ and $\beta_{2}<0$. This indicates that the relation between environment degradation and development shows a MEKC shape. These results add evidence to the literature supporting that $\mathrm{CO}_{2}$ is generally believed to be the most likely indicator that would follow the inverted-U hypothesis. The results estimated in subset (1) indicate the existence of a MEKC for the MENA economies. This means that when the economy is at a less developed, the environment degradation increases, however, when the country gets reaches a higher level of development, the environment degradation decreases, the environmental awareness of the population gets higher, more clean technology is implemented and the $\mathrm{CO}_{2}$ emissions decrease. In subset (2), the variable indicating corruption control (CORR) is added to the estimation. Yet, the empirical results indicating the validity of MEKC hypothesis still correct. In addition, the sign of the coefficient of CORR is negative as expected and statistically significant at $1 \%$ level of significance. These results mean that with more control for corruption, $\mathrm{CO}_{2}$ emissions can also decrease. The next section adds substantial evidence on the corruption- $\mathrm{CO}_{2}$ emissions relationship.

\section{Granger Causality Test For Carbon Dioxide And Corruption}

Granger causality examines how much of the current values of $\mathrm{Y}$ are explained by previous values of $\mathrm{Y}$ and if the inclusion of lagged values of $\mathrm{X}$ improves the explanation or not. $\mathrm{X}$ is said to Granger-cause $\mathrm{Y}$ if the forecast for $\mathrm{Y}$ is improved when lagged values of $\mathrm{X}$ are taken into account, i.e. the coefficients of lagged values of $\mathrm{X}$ are statistically significant. However, Granger causality measures only the effect of $\mathrm{X}$ in predicting or forecasting $\mathrm{Y}$. Accordingly, the null hypothesis of $\mathrm{X}$ does not Granger-cause $\mathrm{Y}$ is examined. Granger causality examines a two way relationship between two variables in two separate regressions. This is to test whether $\mathrm{X}$ Granger-cause $\mathrm{Y}$ in the first regression and $\mathrm{Y}$ Granger-cause $\mathrm{X}$ in the second regression as follows:

$$
\begin{gathered}
\Delta Y_{i, t}=\left(\operatorname{lagged}\left(\Delta Y_{i, t-1}, \Delta X_{i, t-1}\right)\right)+\epsilon_{1 i, t} \\
\Delta X_{i, t}=\left(\operatorname{lagged}\left(\Delta X_{i, t-1}, \Delta Y_{i, t-1}\right)\right)+\epsilon_{2 i, t}
\end{gathered}
$$

Several researchers studied Granger causality tests in a panel context approach ((Hoffmann, Lee, Ramasamy, \& Yeung, 2005); (Olsen, (2007); (Lee, 2009)). Wright \& Craigwell (2011) examined Granger causality between corruption and economic growth in 42 developing economies using linear and non linear panel techniques over the period 1998 to 2009. Their findings show that the outcome of the causal association depends on the method used; corruption appears to Granger 
cause economic growth when the linear panel causality tests are applied and economic growth seems to Granger lead corruption with the non-linear panel methods.

\subsection{Granger Causality Test specification and data}

The Granger causality test related to $\mathrm{CO}_{2}$ emissions and corruption relationship for MENA economies includes the estimation of the following two equations.

$$
\begin{aligned}
& { }^{\Delta} \operatorname{CORR}_{i, t}=\left(\operatorname{lagged}\left(\Delta \operatorname{CORR} R_{i, t-1}, \Delta C O_{2_{i, t-1}}\right)\right)+\epsilon_{1 i, t} \\
& \Delta \mathrm{CO}_{2_{i, t}}=\left(\operatorname{lagged}\left(\Delta C \mathrm{O}_{2_{i, t-1}}, \Delta C O R R_{i, t-1}\right)\right)+\epsilon_{2 i, t}
\end{aligned}
$$

where CORR is the level of control of corruption in MENA economies, $\mathrm{CO}_{2}$ is carbon dioxide emissions per capita to measure environment degradation in MENA economies, and $\varepsilon$ it is the error term for this OLS estimation at time $t$ for country $i$. The first regression is to test whether $\mathrm{CO}_{2}$ emissions Granger-cause corruption; and whether corruption Granger-cause $\mathrm{CO}_{2}$ emissions for the MENA economies is tested in the second regression. The data of MENA economies is the same sample and listed in Appendix (A). Also, the years studied are from 2004-2013. $\mathrm{CO}_{2}$ is measured as $\mathrm{CO}_{2}$ emissions tons per capita and CORR measures the control of corruption; it ranges from app. -2.5 (weak) to 2.5 (strong) governance performance). The data of $\mathrm{CO}_{2}$ are collected from the World Bank Open Data Base. Missing data of $\mathrm{CO}_{2}$ were calculated through the use of linear interpolation. The data of CORR is obtained from the Worldwide Governance Indicators. Given the moderate size of the sample data, the number of lags is chosen to be two to save degrees of freedom.

\subsection{Granger Causality Results for MENA Economies}

Table (2) shows summary of Granger causality results for equations (6) and (7). The results indicate there is Granger causality between corruption and $\mathrm{CO}_{2}$ emissions that runs in one direction.

Table 2: Granger Causality Test Results for MENA Countries*

\begin{tabular}{|l|c|c|c|}
\hline Null Hypothesis & F-Statistic & Probability & Decision \\
\hline $\mathrm{CO}_{2}$ does not Granger- cause CORR & 1.87702 & 0.1567 & Accept Null \\
\hline $\mathrm{CORR}$ does not Granger- cause $\mathrm{CO}_{2}$ & 3.60064 & 0.0297 & Reject Null \\
\hline
\end{tabular}

*The results are for all coefficients jointly to test for Granger Causality in the case of a two period lags.

At $5 \%$ level of significance, the null hypothesis of the first estimation which is $\mathrm{CO}_{2}$ does not Granger-cause CORR is accepted; this means that $\mathrm{CO}_{2}$ does not Granger-cause corruption in the MENA region. The null hypothesis of the second estimation which is CORR does not Grangercause $\mathrm{CO}_{2}$ is rejected. It means that corruption Granger-cause $\mathrm{CO}_{2}$ emissions in MENA region. These results indicate that there is a one way relationship between corruption and $\mathrm{CO}_{2}$ emissions in MENA region. However, if a larger sample is available, the results are expected to be a two way relationship as test results is known to be influenced by the method applied and the sample size.

\section{Conclusion and Policy Recommendations}

The region hosts more than $52 \%$ of the world's oil reserves and $42 \%$ of its gas reserves; yet, it also has important solar resources, which provide an excellent basis to build a renewable energy market. Taking advantage of the international support and finance for climate change mitigation can help MENA economies adopt a path to a lower carbon future by promoting energy efficiency, adopting and financing new clean technologies. Acknowledging the significant of the relationship between corruption and environment quality, one can note that a 
comprehensive approach towards an active solution should include good governance that promote accountability as well as combat corruption. An effective and transparent system for measuring, reporting emissions is crucial to reduce GHG emissions at the national level and ultimately to the success of financing mitigation strategies. Careful monitoring, quick learning and active responding to close entry points for corruption are essential to ensure that strong good governance generates supportive conditions for climate mitigation at this critical stage. To this end, promoting accountability and implementing anti-corruption efforts, will enable and prioritize sustainable development. For example, this can involve the following recommendations;

1. Setting environmental regulations and institutions is a first step in order to improve the environmental quality; however, ensuring good governance for investigating major challenges towards tackling climate change is much more important and vital step.

For example, more than 1500 local authorities around the world have made commitments to ambitious targets for reducing GHG emissions, and Most of MENA economies have a dedicated Ministry for environment and specific legislations for different environmental areas like Water, Soil, and Air pollution... In some countries specific agencies even dedicate themselves for specific challenges: e.g. (i) the identification and measurement of pollution sources, and (ii) setting effective policies and regulation. However, more resources and training are needed to improve the verification of emissions data; in developing countries, a lack of technical capacity or financial resources makes the development of ongoing emissions data collection difficult.

2. Setting effective institutions for the enforcement of environmental legislation

Governments need to perform their functions as providers of public services and enforcers of contracts, in an effective, efficient and transparent manner. Public sector institutions need to be reformed to encourage private sector investment to abide by the environment regulation and make sure they are effectively enforcing accountability. If climate governance is not prepared for corruption, corruption will undermine climate governance. This research provides a risk map to make climate change measures more effective. Recommendations include:

- Transparent climate procedures at the international and local levels that involve all interested parties.

- Experts monitoring and verifying projects must be independent and not paid from the budget of the project they are supervising.

- All climate measures should have strong, well-resourced entities.

- Civil society must monitor government commitments to reduce emissions and be involved in development and oversight of national plans for mitigation and adaptation.

\section{References}

Banuri,Tariq, \& Opschoor, Hans. (2007). Climate Change and Sustainable Development (Working Paper No.56). Retrieved from United Nations DESA website: http://www.un.org/en/development/desa/papers/w56.

Bouvier, Rachel.A. (2004). Air pollution and per capita income; A Disaggregation of the Effects of Scale, Sectoral Composition, and Technological Change (Working paper No.84). Retrieved from University of Massachusetts Amherst Political Economy Research Institute website: http://www.peri.umass.edu /papers/w84.

Costantini, Valeria, \& Martini, Chiara. (2006). A Modified Environmental Kuznets Curve for Sustainable Development Assessment Using Panel Data_(Working Paper No. 148.06). Retrieved from Fondazione Eni Enrico Mattei website: http//www.feem.it/papers/w148.06

Dow, Kirstin, \& Downing, Thomas E. (2006). The Atlas of climate change: mapping the world's greatest challenge. UK: Myriad Editions Press.

Downie, David L., Brash, Kate, \& Vaughan, Catherine. (2009). Climate change: a reference book, Contemporary world issues. USA: ABC-CLIO, Inc. 
Economic Research Forum (ERF). (2010). Income Level and Environmental Quality in the MENA Countries: Discussing the Environmental Ku₹nets Curve Hypothesis. Retrieved from Economic Research Forum website: www.erf.org.eg.

Gnocato, Kathleen, Harford, Anika, Jordan, Kailee, \& Shelley, Elizabeth. (2014). Women, Health and Corruption: Redefining Partnerships for Social Change. Retrieved from the Graduate Institute of Geneva website: http://www.graduateinstitute.ch

Grossman, Gene M., \& Krueger, Alan B. (1995). Does the Environmental Kuznets Curve Describe How Individual Countries Behave. The Quarterly Journal of Economics, 110 (2), 353-377.

He, Jie (2003). Is the Environmental Kuznets Curve hypothesis valid for developing countries? A survey. Canada: Université de Sherbrooke.

Hoffmann, Robert, Lee, C., Ramasamy, B., \& Yeung, M. (2005). FDI and pollution: a Granger causality test using panel data. Journal of International Development, 17, 311-317.

Kallbekken, S. (2000). An alternative Environmental Ku₹nets Curve approach to deforestation (Unpublished Master of Science dissertation). University of York, UK.

Lee Chew, Ging (2009). Foreign direct investment, pollution and economic growth: evidence from Malaysia. Applied Economics, 41, 1709-1716.

Matyas, Laszlo, Sevestre, P. (1995). The Econometrics of Panel data: a handbook of the theory with applications, $2^{\text {nd }}$ ed. USA: Kluwer Academic Publishers.

Organization for Economic Co-operation and Development (OECD). (2014). Background Brief: the Rationale for Fighting Corruption. Retrieved from Organization for Economic Cooperation and Development website: http://www.oecd.org.

Olsen, K. H. (2007). The Clean Development Mechanism's contribution to sustainable development: a review of the literature. Climatic Change, 84(1), 59-73.

Pearce, D.W, \& Atkinson, G. D. (1993). Capital theory and the measurement of sustainable development: an indicator of weak sustainability. Ecological Economics, 8, 103-108.

Stern, David I. (2004). Environmental Kuznets curve. Encyclopedia of Energy, 2, 517- 525.

Stern, Nicholas (2006). The Economics of Climate Change: The Stern Review Report. UK: Cambridge University Press.

The World Bank Open data. (Several years). The World Development Indicators. Retrieved from The World Bank Open data website: http://data.worldbank.org/indicator.

The Worldwide Governance Indicators. (Several years). Aggregate indicators of governance. Retrieved from The Worldwide Governance Indicators website: www.govindicators.org.

Transparency International. (2011). Corruption Report Global: Climate change. Retrieved from Transparency International website: http://www.transparency.org.

Transparency International. (2014). FAQS on Corruption. Retrieved from Transparency International website: http://www.transparency.org

United Nations Environment Program (UNEP). (2013). The impact of corruption on climate change: threatening emissions trading mechanisms?. Retrieved from United Nations Environment Program website: http://www.unep.org

World Commission on Environment and Development (WCED). (1987). Report of the World Commission on Environment and Development: Our Common Future. Retrieved from Wikipedia website: www. wikipedia.org/wiki/Our_Common_Future

Wright, Allan S., \& Craigwell, R. (2011). Economic Growth and Corruption In Developing Economies: Evidence From Linear And Non-Linear Panel Causality Tests (Working Paper No.2011). Retrieved from Central Bank of Barbados website: www.centralbank.org.bb/papers/w2011.

Yandle, Bruce, Bhattarai, Madhusudan, \& Vijayaraghavan, Maya. (2002). The Environmental Kuznets curve: a primer (Research Study No.02-1). Retrieved from Property and Environment Research Center website: www. perc. org./PERC Research Study 02-1.

Yongfu, Huang, \& Barker, Terry (2009). The Clean Development Mechanism and Sustainable Development: A Panel Data Analysis. UK: Cambridge University Press.

\section{Appendix A}

The MENA list includes 19 economies: Algeria, Bahrain, Egypt, Jordan, Kuwait, Lebanon, Morocco, Oman, Qatar, Tunisia, United Arab of Emirates, Syrian Arab Republic and Saudi Arab kingdom, Yemen, Iraq, Djibouti, Libya, Iran and West Bank and Gaza. 